\title{
plater: Read, Tidy, and Display Data from Microtiter Plates
}

\section{DOI: $10.21105 /$ joss.00106}

\section{Software}

- Review ¿

- Repository ca

- Archive ¿

\section{Licence}

Authors of JOSS papers retain copyright and release the work under a Creative Commons Attribution 4.0 International License (CC-BY).

\section{Sean $M$ Hughes $^{1}$}

1 University of Washington

\section{Summary}

plater is an $\mathrm{R}$ ( $\mathrm{R}$ Core Team 2016) package that makes it easy to work with data from experiments performed in microtiter plates.

Many scientific instruments (such as plate readers and qPCR machines) produce data in tabular form that mimics a microtiter plate: each cell corresponds to a well as physically laid out on the plate. For experiments like this, it's often easiest to keep records of what was what (control vs. treatment, concentration, sample type, etc.) in a similar plate layout form.

plater defines a simple, plate-shaped file format for data storage, so it's easy to remember the experimental design, and provides functions to seamlessly convert between that format and a tidy (Wickham 2014) data frame that's optimal for analysis. When the instrument produces data that's already tidy, plater helps combine that data with plateshaped experimental metadata. Once the data is tidy, it's sometimes useful to look back at it in plate shape, so plater makes that easy, too.

\section{References}

R Core Team. 2016. R: A Language and Environment for Statistical Computing. Vienna, Austria: R Foundation for Statistical Computing. https://www.R-project.org/.

Wickham, Hadley. 2014. "Tidy Data." Journal of Statistical Software 59 (1): 1-23. doi:10.18637/jss.v059.i10. 